\title{
Severe Acute Respiratory Syndrome Coronavirus 2 Prevalence, Seroprevalence, and Exposure among Evacuees from Wuhan, China, 2020
}

Benjamin D. Hallowell, ${ }^{1}$ Christina M. Carlson, Jesica R. Jacobs, Mary Pomeroy, Jonathan Steinberg, Mark W. Tenforde, Emily McDonald, Loretta Foster, Leora R. Feldstein, Melissa A. Rolfes, Amber Haynes,

Glen R. Abedi, George S. Odongo, Kim Saruwatari, Errin C. Rider, Gina Douville, Neenaben Bhakta,

Panagiotis Maniatis, Stephen Lindstrom, Natalie J. Thornburg, Xiaoyan Lu, Brett L. Whitaker,

Shifaq Kamili, Senthilkumar K. Sakthivel, Lijuan Wang, Lakshmi Malapati, Janna R. Murray,

Brian Lynch, Martin Cetron, Clive Brown, Shahrokh Roohi, Lisa Rotz, Denise Borntrager, Kenta Ishii,

Kathleen Moser, Mohammad Rasheed, Brandi Freeman, Sandra Lester, Kizzmekia S. Corbett,

Olubukola M. Abiona, Geoffrey B. Hutchinson, Barney S. Graham, Nicki Pesik, Barbara Mahon, Christopher Braden, Casey Barton Behravesh, Rebekah Stewart, Nancy Knight, Aron J. Hall, Marie E. Killerby

To determine prevalence of, seroprevalence of, and potential exposure to severe acute respiratory syndrome coronavirus 2 (SARS-CoV-2) among a cohort of evacuees returning to the United States from Wuhan, China, in January 2020, we conducted a cross-sectional study of quarantined evacuees from 1 repatriation flight. Overall, 193 of 195 evacuees completed exposure surveys and submitted upper respiratory or serum specimens or both at arrival in the United States. Nearly all evacuees had taken preventive measures to limit potential exposure while in Wuhan, and none had detectable SARS-CoV-2 in upper respiratory tract specimens, suggesting the absence of asymptomatic respiratory shedding among this group at the time of testing. Evidence of antibodies to SARS-CoV-2 was detected in 1 evacuee, who reported experiencing no symptoms or high-risk exposures in the previous 2 months. These findings demonstrated that this group of evacuees posed a low risk of introducing SARSCoV-2 to the United States.

Author affiliations: Centers for Disease Control and Prevention, Atlanta, Georgia, USA (B.D. Hallowell, C.M. Carlson, J.R. Jacobs, M. Pomeroy, J. Steinberg, M.W. Tenforde, E. McDonald, L. Foster, L.R. Feldstein, M.A. Rolfes, A. Haynes, G.R. Abedi, G.S. Odongo, P. Maniatis, S. Lindstrom, N.J. Thornburg, X. Lu, B.L. Whitaker,

S. Kamili, S.K. Sakthivel, L. Wang, L. Malapati, J.R. Murray,

B. Lynch, M. Cetron, C. Brown, S. Roohi, L. Rotz, D. Borntrager, K. Ishii, K. Moser, B. Freeman, N. Pesik, B. Mahon, C. Braden,

C. Barton Behravesh, R. Stewart, N. Knight, A.J. Hall, M.E. Killerby);
$\mathrm{O}$ n December 31, 2019, a cluster of severe pneumonia cases in Wuhan, Hubei Province, China, was reported (1). On January 7, 2020, a novel coronavirus, severe acute respiratory syndrome coronavirus 2 (SARS-CoV-2), was isolated from samples associated with the cluster $(2,3)$. As of May 1, 2020, a total of $3,175,207$ coronavirus disease (COVID-19) cases had been confirmed and 224,172 persons had died worldwide; 84,385 cases and 4,643 deaths were in China (4). Also as of May 1, 2020, the US Centers for Disease Control and Prevention (CDC) was reporting ongoing worldwide transmission (5).

On January 20, 2020, a case of coronavirus disease (COVID-19) was confirmed in a US patient who had recently traveled to Wuhan (6). To slow the spread of the epidemic, on January 23, the government of China enacted a travel ban restricting all travel into and out of Wuhan, including air and rail travel, and

Riverside University Health System-Public Health, Riverside, California, USA (K. Saruwatari, E.C. Rider, G. Douville, N. Bhakta); Synergy America Inc., Duluth, Georgia, USA (M. Rasheed, S. Lester); National Institutes of Health, Bethesda, Maryland, USA (K.S. Corbett, O.M. Abiona, G.B. Hutchinson, B.S. Graham) DOI: https://doi.org/10.3201/eid2609.201590

${ }^{1}$ Current affiliation: Department of Health, Providence, Rhode Island, USA 
suspending operation of buses, subways, and ferries within the city (7). As of January 23, a total of 571 confirmed COVID-19 cases had been reported in China (8).

After China enacted the travel ban, the US Department of State planned evacuation flights for US citizens and other third country nationals in Wuhan. We describe the demographic and clinical characteristics, potential exposures to SARS-CoV-2, personal protective measures implemented, and SARS-CoV-2 real-time reverse transcription PCR (rRT-PCR) and serologic test results for evacuees from 1 repatriation flight from Wuhan. These data can be used to better determine SARS-CoV-2 epidemiology, including assessing the point prevalence of past and current SARS-CoV-2 infections in this cohort and identifying factors associated with infection in this cohort. These findings can also be used to help estimate the initial risk for transmission to contacts in the United States posed by evacuees from Wuhan and are relevant to current and future implementation of public health control measures, such as isolation and quarantine.

\section{Methods}

We investigated quarantined evacuees from a January 28, 2020, repatriation flight from Wuhan to the United States. Before the flight departed Wuhan, evacuees were evaluated to ensure that they had no fever or respiratory signs/symptoms. At arrival in the United States and again at the quarantine facility, evacuees were asked to complete a US Traveler's Health Declaration form disclosing any symptoms; they were also screened for illness and fever, asked about symptoms in the past 72 hours, and asked about any high-risk exposures (including working in or visiting healthcare settings; caring for or visiting persons with fever, respiratory illness, or a confirmed COVID-19 diagnosis; or visiting any live animal markets) in Wuhan in the past 14 days. Those who reported symptoms or high-risk exposures were evaluated by a CDC Quarantine Medical Officer, who determined if they required further evaluation and isolation from the quarantined cohort.

Nasopharyngeal and oropharyngeal swab samples and serum specimens were obtained from participating evacuees when they arrived at the quarantine station in the United States. As part of quarantine procedures, evacuees were actively monitored for fever and respiratory signs/symptoms for 14 days after departure from Wuhan; any evacuee in whom either fever or respiratory signs/symptoms developed during this time was evaluated for COVID-19 (9), and additional nasopharyngeal and oropharyngeal specimens were collected $(10,11)$. All specimens were collected, processed, and shipped to CDC for testing $(10,11)$. Presence of SARS-CoV-2 in nasopharyngeal and oropharyngeal swab samples was confirmed by rRT-PCR detection of viral RNA in respiratory specimens (12). Serum specimens were initially tested for SARS-CoV-2 antibodies by SARS-CoV-2 ELISA (Appendix 1, https://wwwnc.cdc.gov/EID/ article/26/9/20-1590-App1.pdf).

We asked evacuees to complete a detailed, selfadministered survey during the flight from $\mathrm{Wu}$ han (Appendix 2, https://wwwnc.cdc.gov/EID/ article/26/9/20-1590-App2.pdf). The survey captured information on demographics, clinical signs/ symptoms, travel outside of Hubei Province, face mask use, limitation of time spent in public, and past high-risk exposures (including contact with confirmed COVID-19 case-patients; persons with fever, acute respiratory illness, or both; healthcare and laboratory facilities; and animals and live animal markets). We assessed high-risk exposures over the past 2 weeks and the past 2 months. We compared high-risk exposures over the past 2 weeks with rRT-PCR results for persons who provided an upper respiratory specimen (because 14 days was the upper end of the estimated incubation period for COVID-19 $[13,14])$. We also compared high-risk exposures over the past 2 months with the serologic test results for evacuees who provided a serum sample (because SARS-CoV-2 had probably been circulating for the 2 months before their departure [15]).

We entered survey responses into REDCap electronic data capture tools hosted at CDC (16), and all entries were verified by a second reviewer for accuracy and completeness. Data were analyzed by using SAS software version 9.4 (SAS Institute, Inc., https://www.sas.com).

CDC determined that this investigation was public health surveillance (US Department of Health and Human Services, Title 45 Code of Federal Regulations 46, Protection of Human Subjects). Evacuees' participation in the collection of biological specimens and the survey was voluntary.

\section{Results}

At the time of arrival in the United States, no evacuee had a measured fever or reported any signs or symptoms that required further evaluation. Of the 195 evacuees, 193 completed surveys; 99\% (191/193) of respondents provided a nasopharyngeal sample, an oropharyngeal sample, or 1 of each for SARS-CoV-2 rRT-PCR testing, and 96\% (186/193) provided a serum sample for testing. The median age of all 193 evacuees was 42 (range $0-74)$ years, and 53\% (100/189) were 
male (Table 1). Most were either Asian (49\%, 94/192) or White $(35 \%, 68 / 192)$.

One evacuee reported having had close contact with a person with laboratory-confirmed COVID-19 in the previous 2 weeks. Specifically, reported exposures included direct physical contact, being within 6 feet of the person while that person was coughing or sneezing, taking an object handed from or handled by the person, and traveling in the same vehicle as the person (Table 2). No other evacuees reported exposure to a person with laboratory-confirmed COVID-19 in the previous 2 months. However, 6\% (12/191) reported having had close contact with a person with fever, acute respiratory illness, or both in the previous 2 weeks and $16 \%$ (30/186) in the previous 2 months (Table 2). One evacuee had visited a live animal market in the previous 2 weeks and 5\% (9/186) in the previous 2 months. Three percent $(6 / 191)$ of evacuees had visited settings with nondomesticated live animals in the previous 2 weeks and 5\% (10/186) in the previous 2 months. One percent (2/191) of evacuees had had direct physical contact with a nondomesticated

\begin{tabular}{|c|c|}
\hline Characteristic & $\begin{array}{c}\text { No./total no. } \\
(\%)^{*}\end{array}$ \\
\hline \multicolumn{2}{|l|}{ Age group, y } \\
\hline$<18$ & $32 / 193(17)$ \\
\hline $18-44$ & 68/193 (35) \\
\hline $45-64$ & $83 / 193(43)$ \\
\hline$\geq 65$ & 10/193 (5) \\
\hline \multicolumn{2}{|l|}{ Sex } \\
\hline M & $100 / 189(53)$ \\
\hline $\mathrm{F}$ & $89 / 189(47)$ \\
\hline \multicolumn{2}{|l|}{ Race/ethnicity } \\
\hline White & $68 / 192(35)$ \\
\hline Black & 6/192 (3) \\
\hline Asian & 94/192 (49) \\
\hline Multiracial & $13 / 192(7)$ \\
\hline Hispanic & $11 / 192(6)$ \\
\hline \multicolumn{2}{|l|}{ Underlying medical condition } \\
\hline Chronic lung disease & $1 / 191(1)$ \\
\hline Asthma/reactive airway disease & $7 / 191(4)$ \\
\hline Diabetes mellitus type 1 & $2 / 187(1)$ \\
\hline Diabetes mellitus type 2 & $4 / 191(2)$ \\
\hline Hypertension & $14 / 192(7)$ \\
\hline Chronic heart or cardiovascular disease & $0 / 191(0)$ \\
\hline Chronic kidney disease & $1 / 191(1)$ \\
\hline Liver disease & $1 / 191(1)$ \\
\hline Noncancer immunosuppressive condition & $1 / 189(1)$ \\
\hline Neurologic/neurodevelopmental disorder & $1 / 191(1)$ \\
\hline Other chronic disease & $11 / 191(6)$ \\
\hline \multicolumn{2}{|l|}{ Specimen submitted } \\
\hline $\begin{array}{l}\text { Nasopharyngeal and/or oropharyngeal swab } \\
\text { sample }\end{array}$ & 191/193 (99) \\
\hline Serum & $186 / 193(96)$ \\
\hline
\end{tabular}

live animal (both instances with stray dogs) in the previous 2 weeks. No additional evacuees had had direct physical contact with a nondomesticated live animal in the previous 2 months.

During the previous month, after hearing about COVID-19 cases in Wuhan, 95\% (178/188) of evacuees reported having limited their time in public in Wuhan, including avoiding public gatherings $(87 \%)$, public transportation $(84 \%)$, and all public settings (e.g., grocery stores or restaurants; 70\%) (Table 3). In addition, in the previous month, after hearing about COVID-19 cases in Wuhan, $76 \%$ of evacuees reported having worn a face mask while in public spaces. This finding represented a significant increase from the $34 \%$ of evacuees who reported having worn a face mask while in public spaces in the previous 2 months (McNemar test statistic 74.05; $\mathrm{p}<0.0001)$.

Five percent $(9 / 193)$ of evacuees reported having experienced signs or symptoms associated with COVID-19 (measured or subjective fever, cough, shortness of breath) in the previous 2 weeks, and $12 \%(24 / 193)$ reported signs/symptoms associated with COVID-19 in the previous 2 months. One evacuee who reported signs/symptoms associated with COVID-19 in the previous 2 weeks sought medical care, and no evacuee required hospitalization while in Wuhan (Table 4).

SARS-CoV-2 was not detected by rRT-PCR in any of the 190 nasopharyngeal or 190 oropharyngeal swab specimens collected from 191 unique evacuees (189 provided nasopharyngeal and oropharyngeal samples, 1 nasopharyngeal sample only, and 1 oropharyngeal sample only). During the 14-day quarantine period, fever developed in 2 evacuees; additional nasopharyngeal and oropharyngeal swab specimens were collected and tested, and SARS-CoV-2 was not detected in either specimen type.

One evacuee showed serologic evidence of a past SARS-CoV-2 infection. Serum from that person had antibodies against SARS-CoV-2 at titers of 400 determined by ELISA and 320 determined by microneutralization test. This person was male, was in the 19-44-year age group, was traveling without any family members, and reported no signs/symptoms associated with COVID-19 in the past 2 months. He reported no high-risk exposures (including exposure to or contact with live animals, live animal markets, persons known to be ill with COVID-19, or persons with fever or acute respiratory signs/symptoms). He reported that since early January he had spent limited time out in public, including avoiding public transport, avoiding public gatherings, and not attending 
Table 2. Potential exposures to severe acute respiratory syndrome coronavirus 2 by 193 evacuees returning from Wuhan, China, to the United States, January $2020^{*}$

\begin{tabular}{|c|c|}
\hline Exposure risk factors & No./total no. (\%)† \\
\hline \multicolumn{2}{|l|}{ Relevant exposures for serology results $\ddagger$} \\
\hline \multicolumn{2}{|l|}{ Animal contact } \\
\hline Visited the Huanan Seafood Market in past 2 mo & $1 / 186(1)$ \\
\hline Visited any live animal market in past 2 mo & 9/186 (5) \\
\hline Visited any settings with domesticated animals in past 2 mo & $39 / 186(21)$ \\
\hline Visited any settings with nondomesticated animals in past $2 \mathrm{mo}$ & $8 / 186(4)$ \\
\hline Had direct contact with any animals in past 2 mo & $52 / 186(28)$ \\
\hline \multicolumn{2}{|l|}{ Human contact } \\
\hline Had close contact with laboratory-confirmed COVID-19 case-patient in past 2 mo & $1 / 186(1)$ \\
\hline Had close contact with person with fever and/or acute respiratory illness in past 2 mo & $30 / 186(16)$ \\
\hline \multicolumn{2}{|l|}{ High-risk settings } \\
\hline Visited a healthcare setting (not in United States) in past 2 mo & $8 / 186(4)$ \\
\hline Worked in a healthcare setting in Wuhan in past $2 \mathrm{mo}$ & $0 / 186(0)$ \\
\hline Worked in a laboratory setting in Wuhan in past 2 mo & $0 / 186(0)$ \\
\hline \multicolumn{2}{|l|}{ Travel } \\
\hline Did not travel outside of Hubei Province, China, in past 2 mo & $62 / 186(33)$ \\
\hline \multicolumn{2}{|l|}{ Relevant exposures for PCR results§ } \\
\hline \multicolumn{2}{|l|}{ Animal contact } \\
\hline Visited any live animal market in past 2 wk & $1 / 191(1)$ \\
\hline Visited any settings with domesticated animals in past $2 \mathrm{wk}$ & $15 / 191(8)$ \\
\hline Visited any settings with nondomesticated animals in past $2 \mathrm{wk}$ & $6 / 191(3)$ \\
\hline Had direct physical contact with live domestic animals in past $2 \mathrm{wk}$ & $36 / 191(19)$ \\
\hline Had direct physical contact with live nondomestic animals in past 2 wk & $2 / 191(1)$ \\
\hline \multicolumn{2}{|l|}{ Human contact } \\
\hline Had close contact with laboratory-confirmed COVID-19 case-patient in past 2 wk & $1 / 191(1)$ \\
\hline Had close contact with person with fever and/or acute respiratory illness in past 2 wk & $12 / 191(6)$ \\
\hline \multicolumn{2}{|l|}{ High-risk settings } \\
\hline Visited a healthcare setting (not in United States) in past 2 wk & $7 / 191(4)$ \\
\hline $\begin{array}{l}{ }^{*} \text { COVID-19, coronavirus disease. } \\
\text { †Data for persons for whom responses were missing were excluded from the denominator. } \\
\text { fLimited to exposures within the past } 2 \text { mo and to persons who submitted serum sample. } \\
\text { \$Limited to exposures within the past } 2 \text { wk and to persons who submitted a nasopharyngeal and/or oro }\end{array}$ & \\
\hline
\end{tabular}

school/university. ELISA results for the remaining 185 serum specimens measured SARS-CoV-2 antibody titers at $<400$, and the samples were therefore considered seronegative.

\section{Discussion}

Our report on SARS-CoV-2 prevalence, seroprevalence, and potential exposures among evacuees returning from Wuhan is part of the public health response enacted to slow transmission of SARS-CoV-2 in the United States. Although this population of evacuees is probably not representative of all Wuhan residents in terms of risk of acquiring SARS-CoV-2 infection, our results indicate limited exposure to SARS-CoV-2 among this group of early evacuees from Wuhan.

Compared with previously reported COVID-19 case-patients in Wuhan, our population was younger (median 42 vs. 59 years of age) and their reported frequency of potential SARS-CoV-2 exposures was lower, including exposure to persons with respiratory signs/symptoms, work-associated healthcare exposures, and exposure to live animal markets (15). Of note, although our questionnaire covered exposure to animals and animal markets, most transmission within Wuhan during the evacuees' relevant exposure period before the repatriation flight to the United States was probably human-to-human $(15,17)$. Our study population, which consisted predominantly of US expatriates, probably had other factors that reduced their risk for exposure and were not documented as part of our investigation. For example, it is possible that the expatriates' households in Wuhan were smaller than other households in Wuhan, which has been associated with a lower risk for transmission (18-21); however, because we did not document household size in our investigation, we cannot show such an association. Nearly all evacuees took preventive measures to limit potential exposure to SARSCoV-2 while in Wuhan. However, $16 \%$ of evacuees did have direct contact with persons who had fever or acute respiratory illness.

Previous investigations among evacuees traveling from Wuhan to Germany and Japan detected SARS-CoV-2 RNA in 7 asymptomatic persons $(22,23)$, suggesting that symptom-based screening alone may not be effective for detecting SARS-CoV-2 infection. Evacuees in our study underwent intensive screening such that no evacuee had signs/symptoms at the time of evacuation and none had detectable SARS-CoV-2 
in upper respiratory tract specimens, suggesting the absence of asymptomatic respiratory shedding among this group at the time of testing. In addition, no SARS-CoV-2 was detected in respiratory specimens from the 2 evacuees in whom fever developed during quarantine. The lack of SARS-CoV-2 detection in asymptomatic travelers at the time of testing and in the 2 travelers in whom fever developed could result from a lower risk for exposure among this group compared with Wuhan residents or other reported evacuees $(22,23)$.

The ELISA and microneutralization tests used in this investigation have produced robust responses to serum from confirmed SARS-CoV-2 patients (B. Freeman et al., unpub data, https://www.biorxiv. org/content/10.1101/2020.04.24.057323v2 28). Although 24 evacuees reported signs/symptoms associated with COVID-19 (subjective fever, cough, or shortness of breath) in the previous 2 months, none were seropositive for SARS-CoV-2. In contrast, an antibody response was detected in 1 person who did not report illness in the previous 2 months, indicating past SARS-CoV-2 infection, suggestive of past asymptomatic or mildly symptomatic infection. The overall seroprevalence of $1 \%$ suggests a low level of exposure to SARS-CoV-2 over the preceding 2 months in Wuhan. However, a lack of antibody response may not mean an absence of past infection; serologic responses were not always found in persons with mild Middle East respiratory syndrome coronavirus illness and positive rRT-PCR results for that virus (24). Future serologic testing among COVID-19 case-patients may be useful for determining whether persons with asymptomatic or mild COVID-19 disease become seropositive.
Efforts by this cohort to limit their exposure by limiting their time in public may have helped prevent infection, even in a city with extensive ongoing community transmission. Because SARS-CoV-2 seems to be transmitted primarily through respiratory droplets, limiting time in public may have helped prevent infection because proximity to infected persons is needed for virus transmission (25). Before the evacuees in our study departed Wuhan, China was implementing measures to control SARS-CoV-2 by suspending public transport and vehicle traffic and canceling Lunar New Year gatherings (7). CDC currently recommends that all persons wear cloth face coverings in public; the purpose is to help protect others from potential droplet exposure, not to protect the persons wearing the face coverings (26). Thus, although $76 \%$ of evacuees reported mask use after hearing about COVID-19 in Wuhan, individual mask use probably had minimal effect on their individual risk of acquiring infection.

Information about virus prevalence, seroprevalence, and possible SARS-CoV-2 exposures in this population of evacuees has the potential to inform current and future quarantine and isolation policies. In this population, who underwent intensive screening and monitoring, we detected no evidence of current infection with SARS-CoV-2 and very limited evidence of past infection. Other than the 193 evacuees included in our study, 3 cases of COVID-19 were detected in the United States during quarantine of later cohorts of evacuees after signs/symptoms developed and the evacuees underwent testing, demonstrating the value of quarantine and active monitoring of evacuees to detect COVID-19 cases (27).

\begin{tabular}{|c|c|c|c|}
\hline \multirow[b]{2}{*}{ Precaution } & \multicolumn{3}{|c|}{ No./total no. $(\%) \dagger$} \\
\hline & Total, $n=193$ & $\begin{array}{l}\text { Submitted NP or OP } \\
\text { sample, } \ddagger \mathrm{n}=191\end{array}$ & $\begin{array}{l}\text { Submitted serum } \\
\text { sample, } \S n=186\end{array}$ \\
\hline \multicolumn{4}{|l|}{ Face mask use } \\
\hline Usually wore a face mask in past 2 mo while in public & $63 / 185(34)$ & 63/184 (34) & $63 / 178(35)$ \\
\hline $\begin{array}{l}\text { Usually wore a face mask in past } 1 \text { mo while in public after hearing about } \\
\text { COVID-19 }\end{array}$ & $143 / 188(76)$ & $143 / 187(76)$ & $138 / 181(76)$ \\
\hline \multicolumn{4}{|l|}{ Limited time in public } \\
\hline \multicolumn{4}{|l|}{ By taking the following precautions } \\
\hline Avoided public transport & 150/178 (84) & 148/176 (84) & 144/171 (84) \\
\hline Avoided public gatherings & $154 / 178(87)$ & $153 / 176(87)$ & $148 / 171(87)$ \\
\hline Did not attend work & $53 / 123(43)$ & $53 / 121(44)$ & $53 / 123(43)$ \\
\hline Did not attend school/university\# & 19/30 (63) & 19/30 (63) & $15 / 25(60)$ \\
\hline Avoided all public settings (e.g., grocery stores, restaurants) & $125 / 178(70)$ & $124 / 176(70)$ & $119 / 171(70)$ \\
\hline \multicolumn{4}{|c|}{$\begin{array}{l}{ }^{*} \text { COVID-19, coronavirus disease; NP, nasopharyngeal swab; OP, oropharyngeal swab. } \\
\text { †Data for persons for whom responses were missing were excluded from the denominator. } \\
\text { †Limited to persons who submitted an NP and/or OP specimen. } \\
\text { \&Limited to persons who submitted serum specimen. } \\
\text { TLimited to persons who reported an occupation (other than student, stay-at-home parent, or retired). } \\
\text { \#Limited to persons } 2-18 \text { years of age and those reporting student as occupation. }\end{array}$} \\
\hline
\end{tabular}


Table 4. Signs/symptoms, clinical course, and past medical history for evacuees reporting illness who were on a repatriation flight from Wuhan, China, to the United States in early 2020*

\begin{tabular}{|c|c|c|}
\hline \multirow[b]{2}{*}{ Characteristic } & \multicolumn{2}{|c|}{ No./total no. (\%)† } \\
\hline & $\begin{array}{l}\text { Self-reported illness in past } \\
\quad 2 \mathrm{mo}, \mathrm{n}=39\end{array}$ & $\begin{array}{l}\text { Self-reported illness in past } \\
2 \mathrm{wk}, \mathrm{n}=13\end{array}$ \\
\hline \multicolumn{3}{|l|}{ Sign/symptom } \\
\hline Measured fever & $5 / 36(14)$ & $3 / 12(25)$ \\
\hline Subjective fever & $16 / 37(43)$ & $2 / 13(15)$ \\
\hline Cough & $15 / 36(42)$ & $6 / 12(50)$ \\
\hline Sore throat & $21 / 38(55)$ & $9 / 13(69)$ \\
\hline Muscle aches & $10 / 37(27)$ & $2 / 11(18)$ \\
\hline Headache & $12 / 37(32)$ & $1 / 12(8)$ \\
\hline Shortness of breath & $2 / 34(6)$ & $1 / 12(8)$ \\
\hline Vomiting & $3 / 33(9)$ & $1 / 11(9)$ \\
\hline Diarrhea & $7 / 36(19)$ & $1 / 12(8)$ \\
\hline Fatigue & $16 / 37(43)$ & $3 / 12(25)$ \\
\hline Other & $10 / 30(33)$ & $6 / 10(60)$ \\
\hline Any coronavirus sign/symptom $\ddagger$ & $24 / 39(62)$ & 9/13 (69) \\
\hline Identified as a person under investigation for COVID-19 signs/symptoms§ & $10 / 39(26)$ & $2 / 13(15)$ \\
\hline Sought medical care for illness in past $2 \mathrm{wk}$ & $1 / 39(3)$ & $0 / 13(0)$ \\
\hline \multicolumn{3}{|c|}{$\begin{array}{l}\text { *All persons who self-reported illness submitted serum and a nasopharyngeal or oropharyngeal swab specimen. COVID-19, coronavirus disease. } \\
\text { †Persons for whom responses were missing were excluded from the numerator and denominator. } \\
\text { †Measured fever OR subjective fever, cough, or shortness of breath. } \\
\text { §Measured or subjective fever AND shortness of breath or cough. }\end{array}$} \\
\hline
\end{tabular}

Our investigation has limitations. First, the survey was self-administered and based on self-report; therefore, questions were open to interpretation and subject to reporting bias. Because respiratory specimens from asymptomatic persons were collected at a single point in time, we are unable to show whether asymptomatic shedding might have occurred later during quarantine. Also, rRT-PCR assays and serologic tests are inherently limited by their individual sensitivity and specificity; however, we believe that the limitations of test specificity and sensitivity across this population of evacuees were minimal. In addition, because only 1 serum specimen was taken at the time of US arrival, we were unable to detect antibodies that may have developed later.

As of May 1, a total of 1,062,446 COVID-19 cases had been confirmed in the United States, including 39 in repatriated persons (3 cases in 808 returned evacuees across 5 flights from Hubei Province and 36 cases from the Diamond Princess cruise ship) (28). Initial efforts to slow introduction of SARS-CoV-2 to the United States began in January 2020 and included quarantine of persons with high-risk exposures, screening of travelers at airports, and isolation and contact tracing of confirmed case-patients (28). Our investigation demonstrated that this group of evacuees posed a low risk of introducing SARS-CoV-2 to the United States, and their exposure to SARS-CoV-2 in Wuhan was probably limited. These results should help inform public health guidance on quarantine and isolation measures for travelers arriving from high-risk areas and further characterize the epidemiology of this emerging virus.

\section{Acknowledgments}

We thank the following members of the Riverside University System: Josephine Cortez, Anthony Martinez, Brianna Anderson, Hanh Nguyen, Kim Clifton, Vanessa Arreola, Jarrett Herbst, Jide Adeyeye, Stephanie Loe, Geoffrey Leung, Mike Mesisca, Gregory Harriman. We also thank the CDC COVID-19 Patient Under Investigation Team.

\section{About the Author}

At the time of the study, Dr. Hallowell was an Epidemic Intelligence Service Officer in the Division of Viral Diseases, National Center for Immunization and Respiratory Diseases, CDC. His research interests include epidemiology of infectious diseases, vaccines, and public health.

\section{References}

1. World Health Organization. Pneumonia of unknown causeChina [cited 2020 Feb 20]. https:/ / www.who.int/csr/ don/05-january-2020-pneumonia-of-unkown-cause-china

2. World Health Organization. Novel coronavirus (2019-nCoV) situation report-1: 21 January 2020 [cited 2020 Feb 20]. https://www.who.int/docs/default-source/coronaviruse/ situation-reports/20200121-sitrep-1-2019-ncov.pdf

3. Gorbalenya AE, Baker SC, Baric RS, de Groot RJ, Drosten C, Gulyaeva AA, et al.; Coronaviridae Study Group of the International Committee on Taxonomy of Viruses. The species Severe acute respiratory syndrome-related coronavirus: classifying 2019-nCoV and naming it SARS-CoV-2. Nat Microbiol. 2020;5:536-44. https:/ /doi.org/10.1038/s41564-020-0695-z

4. World Health Organization. Novel coronavirus (2019-nCoV) situation report-102 [cited 2020 May 1]. https://www.who.int/docs/default-source/coronaviruse/ situation-reports/20200501-covid-19-sitrep.pdf 
5. Centers for Disease Control and Prevention. Coronavirus disease 2019 [cited 2020 May 1]. https:/ / www.cdc.gov/ coronavirus/2019-ncov/travelers/index.html

6. Holshue ML, DeBolt C, Lindquist S, Lofy KH, Wiesman J, Bruce H, et al.; Washington State 2019-nCoV Case Investigation Team. First case of 2019 novel coronavirus in the United States. N Engl J Med. 2020;382:929-36. https:/ / doi.org/10.1056/NEJMoa2001191

7. Chinazzi M, Davis JT, Ajelli M, Gioannini C, Litvinova M, Merler S, et al. The effect of travel restrictions on the spread of the 2019 novel coronavirus (COVID-19) outbreak. Science. 2020; 368:395-400. https:/ / doi.org/10.1126/science.aba9757

8. World Health Organization. Novel coronavirus (2019-nCoV) situation report-3: 23 January 2020 [cited 2020 Mar 27]. https://www.who.int/docs/default-source/coronaviruse/ situation-reports/20200123-sitrep-3-2019-ncov.pdf

9. Centers for Disease Control and Prevention. Evaluating and testing persons for coronavirus disease 2019 (COVID-19) [cited 2020 Mar 27]. https:/ / www.cdc.gov/ coronavirus/2019-nCoV/hcp/clinical-criteria.html

10. Centers for Disease Control and Prevention. Interim guidelines for collecting, handling, and testing clinical specimens from persons under investigation (PUIs) for 2019 novel coronavirus (2019-nCoV) [cited $2020 \mathrm{Feb} 12]$. https:/ / www.cdc.gov/coronavirus/2019-nCoV/lab/ guidelines-clinical-specimens.html

11. Centers for Disease Control and Prevention. Interim laboratory biosafety guidelines for handling and processing specimens associated with 2019 novel coronavirus (2019-nCoV) [cited 2020 Feb 12]. https:/ / www.cdc.gov/ coronavirus/2019-nCoV/lab/lab-biosafety-guidelines.html

12. Centers for Disease Control and Prevention. Real-time RT-PCR panel for detection 2019-novel coronavirus [cited 2020 May 18]. https:/ / www.cdc.gov/coronavirus/ 2019-ncov/lab/guidelines-clinical-speciments.html

13. Patel A, Jernigan DB; 2019-nCoV CDC Response Team. Initial public health response and interim clinical guidance for the 2019 novel coronavirus outbreak - United States, December 31, 2019-February 4, 2020. MMWR Morb Mortal Wkly Rep. 2020;69:140-6. https:// doi.org/10.15585/ mmwr.mm6905e1

14. Backer JA, Klinkenberg D, Wallinga J. Incubation period of 2019 novel coronavirus (2019-nCoV) infections among travellers from Wuhan, China, 20-28 January 2020. Euro Surveill. 2020;25:2000062. https://doi.org/10.2807/ 1560-7917.ES.2020.25.5.2000062

15. Li Q, Guan X, Wu P, Wang X, Zhou L, Tong Y, et al. Early transmission dynamics in Wuhan, China, of novel coronavirus-infected pneumonia. N Engl J Med. 2020;382:1199-207. https:// doi.org/10.1056/NEJMoa2001316

16. Harris PA, Taylor R, Thielke R, Payne J, Gonzalez N, Conde JG. Research electronic data capture (REDCap) - a metadata-driven methodology and workflow process for providing translational research informatics support. J Biomed Inform. 2009;42:377-81. https:/ / doi.org/10.1016/ j.jbi.2008.08.010

17. Hui DSI, I Azhar E, Madani TA, Ntoumi F, Kock R, Dar O, et al. The continuing 2019-nCoV epidemic threat of novel coronaviruses to global health - the latest 2019 novel coronavirus outbreak in Wuhan, China. Int J Infect Dis. 2020;91:264-6. https:// doi.org/10.1016/j.ijid.2020.01.009

18. Sjödin H, Wilder-Smith A, Osman S, Farooq Z, Rocklöv J. Only strict quarantine measures can curb the coronavirus disease (COVID-19) outbreak in Italy, 2020. Euro Surveill. 2020;25:2000280. https:// doi.org/10.2807/1560-7917. ES.2020.25.13.2000280

19. Sun K, Viboud C. Impact of contact tracing on SARS-CoV-2 transmission. Lancet Infect Dis. 2020;S1473-3099(20)30357-1.

20. Li W, Zhang B, Lu J, Liu S, Chang Z, Cao P, et al. The characteristics of household transmission of COVID-19. Clin Infect Dis. 2020 Apr 17 [Epub ahead of print]. https://doi.org/10.1093/cid/ciaa450

21. Bi Q, Wu Y, Mei S, Ye C, Zou X, Zhang Z, et al. Epidemiology and transmission of COVID-19 in 391 cases and 1286 of their close contacts in Shenzhen, China: a retrospective cohort study. Lancet Infect Dis. 2020; S1473-3099(20)30287-5. https:/ / doi.org/10.1016/ S1473-3099(20)30287-5

22. Hoehl S, Rabenau H, Berger A, Kortenbusch M, Cinatl J, Bojkova D, et al. Evidence of SARS-CoV-2 infection in returning travelers from Wuhan, China. N Engl J Med. 2020;382:1278-80. https:// doi.org/10.1056/NEJMc2001899

23. Nishiura H, Kobayashi T, Yang Y, Hayashi K, Miyama $\mathrm{T}$, Kinoshita R, et al. The rate of underascertainment of novel coronavirus (2019-nCoV) infection: estimation using Japanese passengers data on evacuation flights. J Clin Med. 2020;9:419. https://doi.org/10.3390/jcm9020419

24. Alanazi KH, Killerby ME, Biggs HM, Abedi GR, Jokhdar H, Alsharef AA, et al. Scope and extent of healthcare-associated Middle East respiratory syndrome coronavirus transmission during two contemporaneous outbreaks in Riyadh, Saudi Arabia, 2017. Infect Control Hosp Epidemiol. 2019;40:79-88. https://doi.org/10.1017/ice.2018.290

25. Wilder-Smith A, Freedman DO. Isolation, quarantine, social distancing and community containment: pivotal role for old-style public health measures in the novel coronavirus (2019-nCoV) outbreak. J Travel Med, 2020;27(2), taaa020. https://doi.org/10.1093/jtm/taaa020

26. Centers for Disease Control and Prevention. How to protect yourself \& others [cited 2020 Apr 14]. https://www.cdc. gov/coronavirus/2019-ncov/ prevent-getting-sick/ prevention.html

27. Centers for Disease Control and Prevention. Coronavirus disease 2019 (COVID-19): cases in the U.S. [cited 2020 May 1]. https://www.cdc.gov/coronavirus/2019-ncov/ cases-in-us.html

28. Jernigan DB; CDC COVID-19 Response Team. Update: public health response to the coronavirus disease 2019 outbreak - United States, February 24, 2020. MMWR Morb Mortal Wkly Rep. 2020;69:216-9. https://doi.org/10.15585/ mmwr.mm6908e1

Address for correspondence: Marie E. Killerby, Centers for Disease Control and Prevention, 2500 Century Ctr, MailstopV25-1, Atlanta, GA 30345, USA; email: 1xo9@cdc.gov 